\title{
Osteoarthritis in the neonate: risk factors and outcome
}

\section{ABSTRACT}

Objectives: The aim of this study was to identify the clinical, radiological, and bacteriological features, risk factors, and outcome of neonates with bone and joint infections. Study design: Observational, retrospective, and analytical study of 77 patients less than 2 months of age, admitted to a tertiary neonatal intensive care unit (NICU) with the diagnosis of bone or joint infection, based on clinical, radiological, and microbiological criteria. Results: Seventy-seven patients with 99 acute osteoarthritis foci in a 16 year period were included in the study. Risk factors for infection could be identified in $69 \%$ of the patients. The hip was the most frequent. Staphylococcus aureus was the main isolated microorganism. Twenty-nine infants (38\%) had sequelae. Hip involvement, culture positive, and Staphylococcus aureus isolation were risk factors associated with sequelae. Conclusion: Osteoarticular infection is unusual in the neonate; however it is associated with an elevated incidence of sequelae. This mandates for a high degree of suspicion to diagnose this potentially disabling entity.

Keywords: osteoarthritis, neonate, Staphylococcus aureus.

[Braz J Infect Dis 2010;14(4):413-418] @Elsevier Editora Ltda.

\section{INTRODUCTION}

Acute osteoarthritis $(\mathrm{AO})$ in the neonatal period is uncommon. The estimated incidence is 1 to 3 cases per 1000 admissions in Neonatal Intensive Care Units ${ }^{1}$ Clinical features, microbiology, and outcome differ from that of older children. Diagnosis may be difficult and delayed because of the paucity signs and symptoms. Poor outcome is related to its potential to cause permanent sequelae., ${ }^{2,3}$

The aim of this investigation was to identify the clinical and radiological features, microbiology, risk factors for sequelae, and outcome of neonates with $\mathrm{AO}$ infection.

\section{PATIENTS AND METHODS}

We included all patients with less than two months of age admitted to the Neonatal Intensive Care Unit (NICU) of the Hospital Nacional de Pediatría "Prof. Dr. Juan P. Garrahan", Buenos Aires, Argentina, over a period of 16 years (1988 -2004). This unit admits about 700 neonates per year and is a tertiary referral center in the country.
The diagnosis of bone or joint infection was based on clinical, radiological, and microbiological criteria. At least two of the following criteria had to be met for inclusion in the study: 1) clinical symptoms; 2) radiological changes; 3) positive blood or bone or joint cultures; 4) aspiration of pus from bone or joint.

Outcome was evaluated by an orthopedic surgeon, an infectologist, and a neonatologist on the basis of radiographic and clinical features. Sequelae included ambulatory disability, limb-length discrepancy, and bone growth abnormalities.

Mild sequelae were defined as local swelling or pain or limited motility and radiographic changes consisting of lytic lesions limited to less than one-third of the bone shaft, a periosteal reaction or sclerosis. Severe sequelae were defined as any symptom at the infection site and radiographic changes consisting of lytic lesions extending over onethird of the bone shaft or lesions within the growth plaque. Radiographic classification (I-V) proposed by Hunka et al. was used for hip infection. ${ }^{4}$
Authors

Griselda Berberian, $\mathrm{MD}^{\mathrm{B}}$

Verónica Firpo, $\mathrm{MD}^{1}$

Adriana Soto, $\mathrm{MD}^{1}$

Julio Lopez Mañan, MD ${ }^{1}$

Cecilia Torroija, $\mathrm{MD}^{1}$

Graciela Castro, $\mathrm{MD}^{1}$

Pablo Polanuer, $\mathrm{MD}^{2}$

Camilo Espinola, $\mathrm{MD}^{2}$

José Luis Piñeiro, $\mathrm{PhD}^{3}$

María Teresa Rosanova, $\mathrm{MD}^{1}$

${ }^{1}$ Department of Infectious Diseases*

${ }^{2}$ Orthopaedic Surgery*

${ }^{3}$ Microbiology*

*Hospital de Pediatría JP Garrahan, Buenos Aires, Argentina.
Submitted on: 05/10/2009 Approved on: 02/03/2010

Correspondence to: Griselda Berberian MD Pico 2265 1429 Buenos Aires Argentina

Phone: +54-11-47031188 E-mail: griselberberian@ yahoo.com.ar

We declare no conflict of interest. 


\section{STATISTICAL ANALYSIS}

All data were entered and verified with the use of Epi-Info 6.0. Statistical Data are summarized as mean or median, range for continuous variables, frequency and percentages for categorical data. Comparative analyses of categorical data were performed by chi-square analysis. P-values $<0.05$ were considered as statistically significant. Statistical analyses were calculated with $95 \%$ confidence intervals.

\section{RESULTS}

We included 77 patients with $99 \mathrm{AO}$ foci. The mean age was 21 (range: $2-53$ ) days, 42 patients (55\%) were male. Mean gestational age at birth was 38 (range: 2642 ) weeks. Of all patients, 49 (64\%) had nosocomial infections, and at least one risk factor for infection was present in 53 (69\%) patients: high-risk pregnancy in 19 (25\%), prematurity in $15(20 \%)$, birth weight less than $1500 \mathrm{~g}$ in $5(7 \%)$, asphyxia in $16(21 \%)$, central catheterization in $24(31 \%)$, mechanical ventilation in $11(14 \%)$, and previous antibiotics in $35(45 \%)$. Less than $4 \%$ of patients had a history of surgery, necrotizing enterocolitis or steroid medication (Table 1).

Table 1. Characteristics of patients

\begin{tabular}{lcc}
\hline Variable & n:77 & \\
\hline Age (median in days) & 21 (r 2-53) & - \\
\hline Male & 42 & 55 \\
\hline Risk factor for infection & 53 & $\mathbf{6 9}$ \\
\hline High risk pregnancy & 19 & 25 \\
\hline Prematurity & 15 & 20 \\
\hline BW < 1500 g & 5 & 7 \\
\hline Asphyxia & 16 & 21 \\
\hline Central catheter & 24 & 31 \\
\hline Mechanical ventilation & 11 & 14 \\
\hline Previous ATB & 35 & 45 \\
\hline Nosocomial infection & 49 & $\mathbf{6 4}$ \\
\hline Time to diagnosis & 2 (r 1-15) & \\
\hline Fever & 39 & 50 \\
\hline Pain & 69 & 90 \\
\hline ESD (median) & $52(\mathrm{r} 5-145)$ & \\
\hline Positive cultures & 66 & 84 \\
\hline Initial abnormal Rx & 29 & 38 \\
\hline Sequelae & $\mathbf{2 9}$ & $\mathbf{3 8}$ \\
\hline Mortality & 1 & 1 \\
\hline & & \\
\hline
\end{tabular}

Fourteen patients (18\%) had multiple joint involvement. The lower extremities were the most commonly affected with 79 foci $(80 \%)$. The hip was the most frequent focus affecting 47 (60\%), followed by the knee in 23 (30\%). Nineteen foci were localized in the upper extremities (20\%), 12 of them $(66 \%)$ in the shoulder (Table 2 ).

Table 2. Distribution of affected bone and joint n: 99 sites in 77 newborn

\begin{tabular}{lcc}
\hline Bone/joint & Number of sites & $\%$ \\
\hline Hip & 47 & 47.5 \\
\hline Knee & 23 & 23.3 \\
\hline Shoulder & 12 & 12.2 \\
\hline Ankle & 8 & 8 \\
\hline Elbow & 6 & 6 \\
\hline Others & 3 & 3 \\
\hline Total & 99 & 100 \\
\hline
\end{tabular}

The median time to diagnosis was two days (range: $1-15)$. The most common clinical presentation was pain in 69 patients (90\%), motor disability in $71(96 \%)$, tenderness in $58(75 \%)$, and erythema in $35(45 \%)$. Fever and sepsis were present in 38 patients (50\%). Forty-seven percent of the patients presented local signs of infection solely.

The median peripheral white blood cell count was $15.900 / \mathrm{mm}^{3}$ (r: $\left.4.500-37.000\right)$ with $70 \%$ polymorhonuclear leukocytes. Erythrocyte sedimentation rates (ESR) were abnormal at initial evaluation in 72 patients (93\%). Cultures were positive in $66(84 \%)$ : joint cultures in $53(82 \%)$, and blood cultures in $35(54 \%)$. The predominant causative organism was Staphylococcus aureus 37 patients (57\%), 19 were methicillin susceptible (Table 3).

Table 3. Microbiology of bone and joint infection n: 66 isolation

\begin{tabular}{lcc}
\hline Organisms & Number of cases & $\%$ \\
\hline Staphylococcus aureus & 37 & 56 \\
\hline Gram-negative enteric bacilli: & 16 & 24.3 \\
Klebsiella pneumoniae & 8 & - \\
Pseudomona aeruginosa & 3 & - \\
Serratia marscecens & 1 & - \\
Proteus mirabilis & 1 & - \\
Acinetobacter baumanii & 1 & - \\
Enterobacter cloacae & 1 & - \\
Escherichia coli & 1 & - \\
\hline Streptococcus agalactiae & 10 & 15.2 \\
\hline Staphylococcus epidermidis & 2 & 3 \\
\hline Haemophilus influenzae type $b$ & 1 & 1.5 \\
\hline Total & 66 & 100 \\
\hline
\end{tabular}


Forty-nine patients acquired infection at the hospital, 39 $(80 \%)$ of them with microbiological isolation. Community infection were acquired in 28 patients, 27 (96\%) of them with positive culture. Relationship between risk factors and etiology is showed in (Table 4).

Table 4. Risk factor and microbiological isolation

\begin{tabular}{|c|c|c|c|c|c|c|}
\hline $\begin{array}{l}\text { Organisms } \\
n=66\end{array}$ & $\begin{array}{l}\text { Commu- } \\
\text { nity } \\
\text { Acquired }\end{array}$ & $\begin{array}{c}\text { Noso- } \\
\text { comial } \\
\text { Infection }\end{array}$ & $\begin{array}{l}\mathrm{CVC} \\
\mathrm{v}\end{array}$ & $\begin{array}{l}\text { Mecha- } \\
\text { nical } \\
\text { entilatio }\end{array}$ & $\begin{array}{l}\text { NEC } \\
\text { n }\end{array}$ & Cort \\
\hline $\begin{array}{l}\text { S. aureus } \\
(\mathrm{n}=37)\end{array}$ & $\begin{array}{c}15 \\
(40 \%)\end{array}$ & $\begin{array}{c}22 \\
(60 \%)\end{array}$ & $\begin{array}{c}12 \\
(33 \%)\end{array}$ & $\begin{array}{c}6 \\
(16 \%)\end{array}$ & $\begin{array}{c}2 \\
(5 \%)\end{array}$ & $\begin{array}{c}2 \\
(5 \%)\end{array}$ \\
\hline $\begin{array}{l}\text { S. epidermidis } \\
(\mathrm{n}=2)\end{array}$ & is & $\begin{array}{c}2 \\
(100 \%)\end{array}$ & $\begin{array}{c}2 \\
(100 \%)\end{array}$ & $\begin{array}{c}2 \\
(100 \%)\end{array}$ & 0 & 0 \\
\hline $\begin{array}{l}\text { Gram - } \\
\text { negative) } \\
\text { bacilli (n: 16) }\end{array}$ & $\begin{array}{c}1 \\
(6 \%)\end{array}$ & $\begin{array}{c}15 \\
(94 \%)\end{array}$ & $\begin{array}{c}6 \\
(38 \%)\end{array}$ & $\begin{array}{c}2 \\
(13 \%)\end{array}$ & 0 & 0 \\
\hline $\begin{array}{l}\text { S. agalactiae } \\
(\mathrm{n}=10)\end{array}$ & $\begin{array}{c}10 \\
(100 \%)\end{array}$ & 0 & 0 & 0 & 0 & 0 \\
\hline H. influenzae & 1 & 0 & 0 & 0 & 0 & 0 \\
\hline $\mathrm{n}$ & 27 & 39 & 20 & 10 & 2 & 2 \\
\hline
\end{tabular}

$\overline{\mathrm{CVC}}$, Cenral vascular catheterization; NEC, necrotizing enterocolitis; Cort, steroid.

Considering nosocomial acquired infection (49), all of them presented with local symptomatology and only 23 patients $(47 \%)$ with systemic manifestation such as fever and sepsis. The median time to the diagnosis was two days (r: 1-15d).

Bone radiological changes were observed in 29 patients $(38 \%)$ at the initial evaluation; osteolytic lesions were the most frequently observed radiographic images (Figure 1).

Figure 1: Severe sequelae of neonatal bone-joint infection in the right hip.

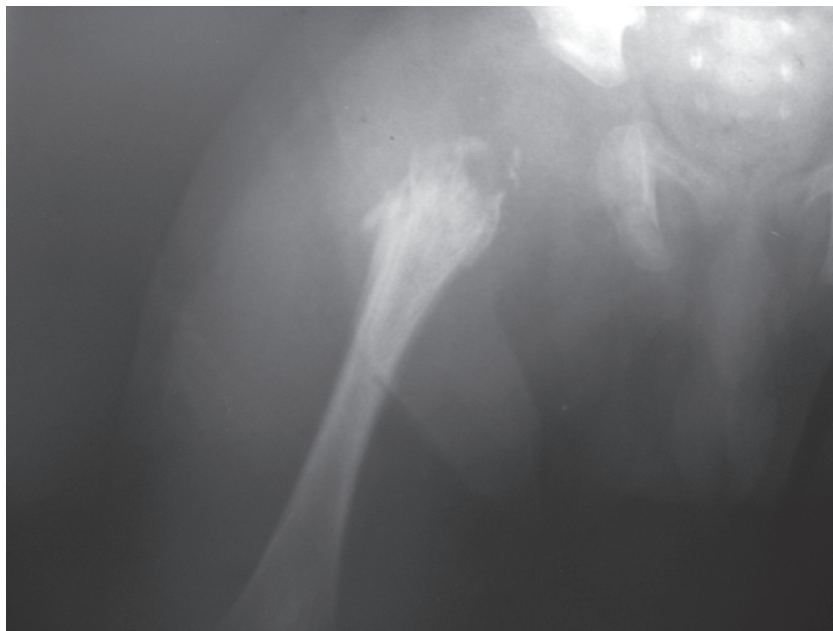

All patients were treated with antibiotics for a median duration of 40 days. Surgical drainage was performed in 58 patients (75\%).One patient (1\%) died because of sepsis.

Twenty-nine infants (38\%) had sequelae. Out of the 29 sequelae, eleven (38\%) were mild and 18 (62\%) severe, considering initial definitions.

By univariate analysis, the risk factors for sequelae were: hip involvement ( $R R=3.15$; 95\% CI: 1.55-6.42; $\mathrm{p}<0.0005)$, positive culture $(\mathrm{RR}=5.25 ; 95 \% \mathrm{CI}: 0.79-35 ; \mathrm{p}<0.02)$, and Staphylococcus aureus isolation ( $\mathrm{RR}=3.17$; 95\% CI: 1.09 9.34; $\mathrm{p}<0.03)$.

\section{DISCUSSION}

In our study the incidence rate of $\mathrm{AO}$ was 7 cases per 1000 admissions, higher than that reported in literature. This may be explained because the Hospital Garrahan is a referral center, where neonates are referred for high risk and surgical management. The frequency of AO did not change along the 16 years of the study. Thus, it appears that neonatal $\mathrm{AO}$ continues to be an uncommon problem.

In the neonate, $\mathrm{AO}$ is usually due to a blood-borne spread of infection to bones or joints. Risk factors are therefore closely related to the risk of bacteremia.

Complications of pregnancy, labor, or delivery precede the occurrence of neonatal $\mathrm{AO}$ in one third to one half of patients. ${ }^{5}$ Associated risk factors included prematurity, low birth weight, asphyxia, bacteremia, and the presence of intravenous or umbilical catheter. ${ }^{6,7}$ In a review of more than 300 cases of neonatal AO, male infants predominate over females $(1,6: 1)$, and premature infants acquire osteoarthritis with a relatively greater frequency than do term infants. ${ }^{8}$ In our study, risk factors for infection were present in 53 patients (69\%); mostly related to nosocomial infections, such as high-risk pregnancies and use of central catheters.

Clinical presentations in the neonate differ from older children. This can be explained partly by the neonate's blood supply to the bone. The metaphyseal vessels communicate with the epiphyseal vessels in the cartilaginous precursor of the ossific nucleus. This facilitates a rapid spread of the infection from the metaphysis to the epiphysis, which is often destroyed, offering a route of infection into the joint. This explains why in the neonate arthritis and osteomyelitis often coexist. ${ }^{9}$

The diagnosis of AO in neonates is often delayed because of nonspecific symptoms, and may be discovered accidentally in the course of routine radiographic examinations, or it may not be apparent until the formation of a local subcutaneous abscess. Local signs may be mild and systemic symptoms may be absent, being irritability the unique sign. ${ }^{10,11,12}$ Clinical presentation may be divided into two groups: The first is the "benign or mild form", 
were preceding bacteremia is of low grade or transient, with a little or no evidence of infection other than local swelling or disability, and symptoms may last for several weeks. The other is the "severe form", where prolonged or intense bacteremia is frequent and systemic manifestations of sepsis predominate with an acute presentation with common multiple joint involvement. ${ }^{13}$

In our patients, as in other reports, the "benign form" was more frequent. Pain and limitation of motion were the most common clinical presentations (90\% and $96 \%$ respectively). Other local signs such as swelling were present in 58 patients (75\%) and erythema in 35 (45\%). Fever was present in only $50 \%$ of the patients.

A report of 485 newborns with $\mathrm{AO}$ the lower extremities was involved in more than $70 \%$, similarly to most reports. ${ }^{13,14}$ Eighty percent of our patients had lower extremities involvement (knee, hip, and ankle), the hip being the most frequent site of infection in 47 patients $(60 \%)$ followed by the knee in 23 patients $(30 \%)$. In the upper extremities, the shoulder was the most frequently involved site.

Multiple bone involvement is more frequent in the newborn, and has been reported in $20 \%$ to $50 \%$ of neonates with OA foci. ${ }^{15}$ In our study there was multifocal involvement in $18 \%$ of the cases.

Plain film radiographs are still the most useful means for establishing the diagnosis of neonatal OA. Neonates show definite signs of bone destruction by the $7^{\text {th }}$ to $10^{\text {th }}$ day of illness. ${ }^{13}$ The use of ultrasonography has been of increasing interest for bone and joint infections. Experience with CT an MRI is limited, as they are used in special situations after the other conventional methods. In our experience, abnormal radiographs were found in $29 \mathrm{pa}$ tients $(37 \%)$ at the initial evaluation.

The white blood cell count (WBC) is of little value in diagnosing neonatal AO. In more than 150 cases, in which these values were recorded, the median WBC count was 17.000 ( $r$ : 4.000-75.000); PMN leucocytes represented about $60 \%$ of WBC. The sedimentation rate is often elevated, and is helpful for diagnosis and follow-up when elevated, but cannot be used to rule out OA infection. ${ }^{17}$ It reacts slowly to resolution of inflammation; frequently, it still rises as clinical improvement occurs. Even when recovery is uneventful, normal rates are not reached until three weeks have elapsed. Alternatively, the C-reactive protein (CRP) is a rapid indicator of inflammation and tissue necrosis and may be useful as an acute phase reactant with more sensitivity in the follow-up. High serial CRP concentration is related with sequelae-prone patients. ${ }^{17-18}$

In our series, the median WBC count was 15.900/ $\mathrm{mm} 3$ with neutrophil predominance $(70 \%)$. ESR was elevated initially in $94 \%$ of the patients. C-reactive pro- tein was not evaluated because it was not performed on a routine basis.

Clinical or radiological evidence of joint-space infection requires confirmation through needle aspiration of an inflammatory area, to establish a rapid means of diagnosis, in addition to the usual sepsis screening studies. In our experience, cultures were positive in 65 patients (84\%), with blood and joint as the most frequent sites of isolation.

Because most cases arise as a consequence of an early bacteremia, the organisms responsible for $\mathrm{AO}$ reflected the etiology of neonatal sepsis. Gram-positive cocci are the most frequently cultured microorganisms representing more than $85 \%$ of isolations, being Staphyloccocus aureus the most common. Streptococcus agalactiae have become increasingly prevalent, as a late-onset illness during the third and forth week of life, usually with a mild presentation. AO caused by Gram-negative enteric bacilli is relatively uncommon despite the frequency of neonatal bacteremia. ${ }^{19}$ In Stockholm, during 1969 to1979, E. coli and Klebsiella-Enterobacter were responsible for about $30 \%$ of neonatal septicemia, but only $5 \%$ of bone infections. 5 In contrast, S. aureus, although also causing about $30 \%$ of neonatal bacteremia, was responsible for $75 \%$ of osteomyelitis.

In our experience, Gram-positive cocci represented $75 \%$ of all isolations. The predominant causative organism was Staphylococcus aureus in 37 patients (57\%). Group B Streptococcus was cultured from 10 patients (15\%), enteric gram-negative bacilli from 16 (24\%), Staphylococcus epidermidis from two, and Haemophilus influenzae type $\mathrm{b}$ from one patient.

Emergence of new pathogens like communityacquired methicillin-resistant Staphylococcus aureus must be considered in newborns with bone and joint infection for empirical treatment. ${ }^{20}$ Successful treatment of osteoarthritis depends on prompt clinical diagnosis and identification of the infectious agent. No controlled studies of type and duration of therapy of these infections exist. General recommendations for antibiotic treatment consider that it should be given by parenteral route initially and continued during 4 to 6 weeks. Peltola et al. propose shorter course of treatment in pediatric patients $>3$ months old, but only few reports is written in newborn patients. ${ }^{21,22}$ Complications encountered during prolonged parenteral antibiotic treatment in children with acute OA infection are related, such as antimicrobial drug reactions and catheter related infections. ${ }^{23}$ Sequential parenteral-oral therapy may be used with close follow-up. Nelson et al. showed that a shorter duration of parenteral therapy followed by an oral therapy based on patient's clinical response was not associated with any recurrence 
of infection. ${ }^{24}$ Longer IV treatments may be needed in those high-risk sequelae-prone patients, depending on localization and microbiology. ${ }^{25}$

In our series, all patients received antibiotic treatment, and 75\% (58) also needed open surgical drainage, especially for hip and shoulder localization.

Treatment duration had a median time of 40 days, with a mean of 21 days of intravenous treatment. Most patients $(91 \%)$ received sequential parenteral- oral treatment. The minority (9\%) received IV antibiotics alone.

The mortality related to $\mathrm{AO}$ is low and is associated with the presence of sepsis. In our experience only one patient died, and it was because of sepsis.

A number of studies document a poor outcome even with modern treatment facilities. Neonatal AO can lead to permanent joint disabilities or disturbances in skeletal growth secondary to damage to the cartilaginous growth plate. These include arthritis, decreased range of motion, limb-length discrepancy, and gait abnormalities. The reported incidence of permanent sequelae varies from $6 \%$ to $50 \% \cdot{ }^{3,6}$ Osteoarticular disabilities was found in $38 \%$ of our patients.

Multiple risk factors are associated with sequelaeprone cases: delay in diagnosis or surgical drainage, involvement of hip or shoulder, short duration of antimicrobial therapy, high serial serum CRP concentrations or high ESR, and slow clinical response to treatment. ${ }^{26}$ Other studies reported that the presence of concomitant osteomyelitis and methicilin-resistant Staphylococcus aureus infection was associated with a significantly increased risk of sequelae. ${ }^{27,28}$

We analyzed risk factors of sequelae in the 77 patients. Adverse outcome was associated with hip involvement, culture positivity, and Stapyloccocus aureus isolation. The other evaluated factors were non-significant for adverse outcome.

\section{CONCLUSIONS}

Bone and joint infections are severe complications in the newborn period. There are risk factors associated with unfavorable outcomes. In our experience, hip involvement and microbiological isolation were risk factors for an unfavorable long-term outcome.

Considering the low incidence, paucity of symptoms, and associated morbidity, a high degree of suspicion is needed to diagnose $\mathrm{AO}$ in the newborn. Appropriate management with antibiotics and surgical drainage in selected cases are important to prevent long term morbidity.

\section{ACKNOWLEGEMENT}

We thank Bes David MD, who gave us the English assistance.

\section{REFERENCES}

1 Goldmann D, Durbin W, Freeman J. Nosocomial infections in a neonatal intensive care unit. J Infect Dis 1981; 144:44959.

2. Bergdahl S, Ekengren k, Erriksson M. Neonatal hematogenous osteomyelitis: risk factors for long-term sequelae. J Pediatr Orthop 1985; 5:564-82.

3. Williamson, Galasko C, Robinson M. Outcome after acute osteomyelitis in preterm infants. Arch Dis Child 1990; 65:1060-2.

4. Hunka L, Said S, Mac Kenzie D, et al . Classification and surgical management of the severe sequelae of septic hips in children. Clin Orthop 1982; 171:30-6.

5. Coto-Cotallo G, Solis-Sanchez G, Crespo-Hernandez M et al. osteomielitis neonatal: estudio de una serie de 35 casos. Ann Esp pediatr 1990; 33:429.

6. Frederiksen B, Christiansen P, Knudsen F et al. Acute oseomyelitis and septic arthritis in the neonate, risk factors and outcome. Eur J Pediatr 1993; 152:577-80.

7. Asmar B. Osteomyelitis in the neonate. Inf Dis Clin of North Am 1992; 6:117-32.

8. Fox L, Sprunt K. Neonatal osteomyelitis. Pediatrics 1978 Oct; 62:535-42.

9. Ogden J. Pediatric osteomyelitis and septic arthritis. The patology of neonatal oseomyelitis. Yale J Biol Med 1979; 52:423-48.

10. Wong M, Isaacs D, Howman- Giles R, Uren R. Clinical and diagnostic features of osteomyelitis occurring in the first three months of life. Pediatr Infect Dis J 1995; 14:1047.

11. Sarlangue J, Castella C, Pontailler J, Chateil J. Neonatal infections of the bone and joints. Archives de Pédiatrie 2007; S108-12.

12. Dan M. Septic arthritis in young infants: clinical and microbiologic correlations and therapeutic implications. Rev Inf Dis $1984 ; 6: 147-55$.

13. Overturf G, Marcy M. Bacterial Infections of the Bones and Joints. In: Remington J and Klein J editors. Infectious Diseases of the Fetus and Newborn Infant. Fifth edition 2001. WB Sounders. Chapter 23; 1019-103.

14. Al Saadi M, Al Zamil FA, Bokary NA et al. Acute septic arthritis in children. Pediatrics International 2009; 51:377-80.

15. Prober C.Clinical approach to the infected neonate. In: Long S, Pickering L- Prober C editors. Principles and practice of pediatric infectious disease. II edition 2006. Chapter 97; 53342.

16. Weinstein M, Stratton C, Hawley $\mathrm{H}$ et al. Multicenter collaborative evaluation of standardize serum bactericidal test as a predictor of therapeutic efficacy in acute and chronic osteomyelitis. Am J Med 1987; 83:218-23.

17 Unkila-Kallio L, Kallio M, Peltola H. The usefulness of C-reactive protein levels in the identification of concurrent septic arthritis in children who have acute hematogenous osteomyelitis. J Bone and Joint Surg 1994; 6:848-53.

18. Roine I, Arguedas A, Faingezicht et al. Early detection of sequela-prone osteomyelitis in children with use of simple clinical and laboratory criteria. Clin Infect Dis 1997; 2:489-53.

19. Dessi A, Crisafulli M, Accossu et al. Osteo-articular infections in newborns: diagnosis and treatment. J Chemother 2008; 20:542-50.

20. Korakaki E, Aligizakis A, Manoura A et al. Methicillin-resistant Staphylococus aureus osteomielitis and septic arthritis in neonates: diagnosis and treatment. JPN J Infect Dis 2007; 60:129-31. 
21. Peltola H, Paakkonen M, Kallio et al. Prospective, randomized trial of 10 days versus 30 days of antimicrobial treatment, including a short term course of parenteral therapy, for childhood septic arthritis. CID 2009; 48:1201-10.

22. Jagodzinski NA, Kanwar R, Graham K, Bache CE. Prospective evaluation of a shortened regimen of treatment for acute osteomyelitis and septic arthritis in children. J Pediatr Orthop 2009; 9:518-25.

23. Ceroni D, Regusci M, Pazos JM et al. Risk and complications of prolonged parenteral antibiotic treatment in children with acute osteoarticular infections. Act Orthop Belg 2003; 69:400-4.

24. Nelson JD. The bacterial etiology an antibiotic management of septic arthritis in infants and children. Pediatrics 1972; 50:437-40.
25. Kim H, Alman B, Cole W. A Shortened course of parenteral antibiotic therapy in de management of acute septic arthritis of the hip. Journal of Pediatric Orthopaedics 2000; 20:44-47.

26. Dagan R, Jacobs RF. Management of acute hematogenous osteomyelitis and septic arthritis in pediatric patient. Pediatr Infect Dis J 1995; 14:40-4.

27. Wang C, Wang S, Yang Y et al. Septic arthritis in children: relationship of causative pathogens, complications, and outcome. J Microbiol Immunol Infect 2003; 36:41-6.

28. Narang A, Mukhopadhyay K, Kumar P et al. Bone and joint infection in neonate. Indian J Pediatr 1998; 65:461-4. 